\title{
RESEARCH ON MISSILE WOUNDS
}

\author{
The Borneo Operations January 1963-June 1965* \\ Brigadier P. ROSS WHEATLEY, D.S.O., F.R.C.S.** \\ Consulting Surgeon, FARELF
}

\section{Introduction}

SURGICAL research may be experimental in the laboratory, on a preplanned clinical basis or a study of the progress and results of a series of cases. The opportunity has been taken in the Borneo campaign to observe the gunshot wounds in men who have been evacuated to the base hospital in Singapore and to benefit from surgical experience by encouraging free criticism of treatment in all stages.

Borneo is a very large island, second in size only to Greenland. The division of the island likens it to an iceberg with its large submerged mass: the upper fraction which used to be coloured red on the map contrasts with the ominous and larger lower fragment of Soekarno's Indonesia. The frontier across it is about 1,000 miles long. North Borneo consists of the states of Sarawak and Sabah which together form Eastern Malaysia and the small independent Sultanate of Brunei which has a valuable oil-field and is under British protection (Fig. 1). The country is heavily wooded and hilly. Roads, except near

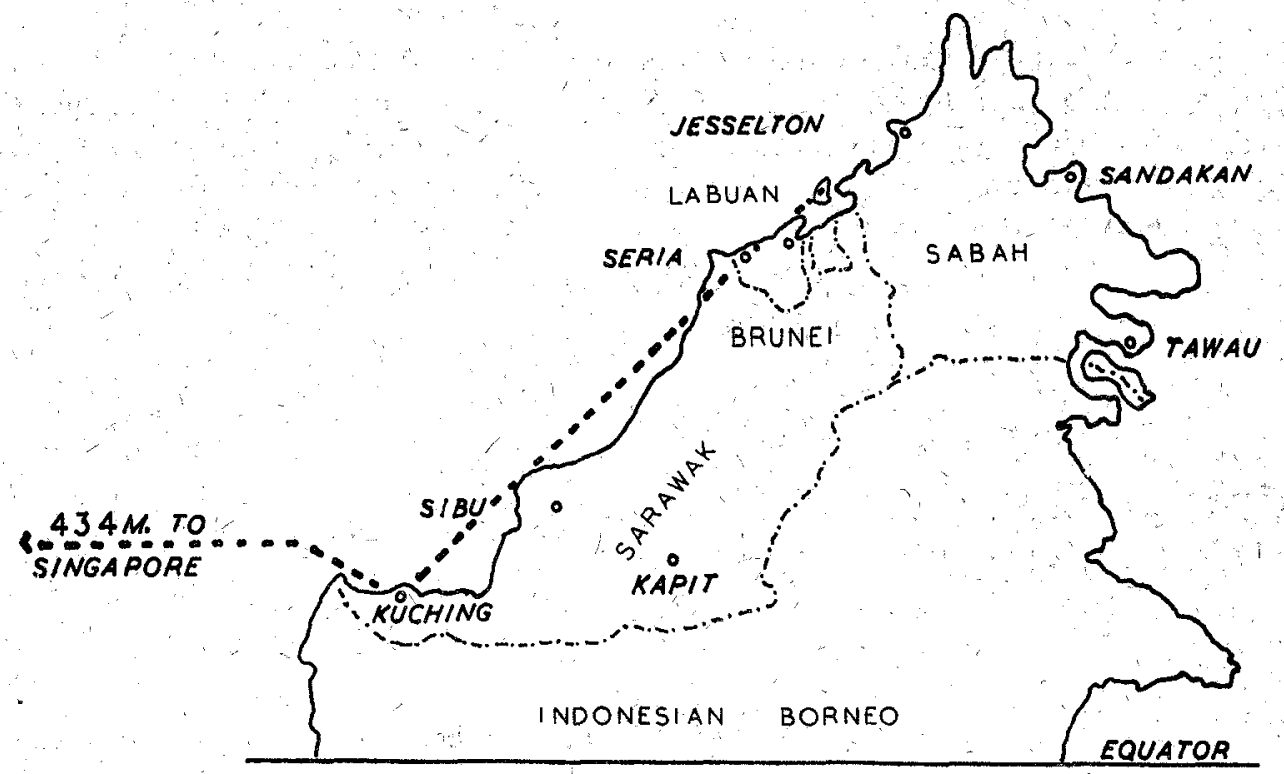

Fig. 1

the big towns on the coast, are non-existent. Tortuous rivers form the natural means of communication with the interior but the main military transport is by air. In the jungle where the troops are fighting the only access is by helicopter.

* A report read at the DGAMS Study Period November 1965.

**Now Consulting Surgeon, H.Q. BAOR, B.F.P.O. 40 


\section{The Borneo Campaign}

The story of violence began suddenly with the Brunei rebellion in December 1962. Marine Commandos and Gurkhas were rushed in and quelled it within a fortnight. Brigadier R. S. Hunt took a surgical team from the British Military Hospital, Singapore, to Labuan Island and dealt with nearly thirty casualties. As the wounds were all caused by small pellets from shotguns they have not been included in the series to be presented. Because of the threat of insurrection in Sarawak as well as in Brunei the troops remained. Then Indonesian confrontation over the frontier demanded a build up which committed large numbers of British and Gurkha, as well as Malaysian, Australian and New Zealand troops over the whole of North Borneo. The surgical team was withdrawn from Labuan after twelve days and for surgical treatment we relied entirely on the civilian hospitals. Casualties were few during 1963 but in March 1964 they began to increase and it became necessary to send a Field Surgical Team (FST) to reinforce the civil hospital in Kuching to which most of the wounded were evacuated. About two thirds of all our wounded passed through this FST. The remainder were treated by civilian surgeons to whose excellent work I would like to pay tribute.

Troops were scattered over a wide front with fortified platoon posts in the jungle. From these small parties of about a section strength moved out in patrol to combat Indonesian incursions. They fought at close range with sub-machine guns, self-loading rifles and grenades. They were exposed to lethal booby traps and were caught by enemy mines. They were mortared and shelled. All this happened deep in the jungle where the only medical aid available was from one of the patrol who carried a small patrol medical pack. No more need be said to emphasise the importance of first aid training for every soldier. He must be taught how to maintain an airway, to apply dressings, to stop haemorrhage, to close a sucking wound of the chest and to improvise the splinting of a limb. This training must be carried out before the unit goes into action; indeed before it embarks for overseas. It will only be done if there is an enthusiastic Regimental Medical Officer (RMO) to supervise it, however many of the non-commissioned officers have attended a first aid course.

\section{The Use of Antibiotics in the Field}

Because there might be a delay of 24 hours or more before a helicopter could reach a casualty it was important that antibiotics were administered early. This antibiotic had to be simple to give and had to withstand the climate without deterioration. Oxytetracylcine ("Terramycin") tablets were included in the patrol pack, two to be taken on wounding and one every six hours afterwards, if the patient could swallow. Drugs for injection, other than morphia in ampoules carried in the patrol pack, were ruled out for the sake of simplicity but as time went on RMOs felt that Gurkha as well as British orderlies could be trained to give an injection.

As there was some doubt whether gastric stasis accompanying the shock of wounding would interfere with the absorption of tetracycline, samples of serum were taken at the FST and sent to Singapore for analysis. Delay in transit of specimens and the sporadic occurrence of wounds made it diffieult to determine the degree of tetracycline absorption. The whole question of the efficacy and durability of antibiotics in a tropical climate needs investigation. 


\section{Supportive Treatment in the Field}

Because of the wide front in deep jungle there was no orthodox line of evacuation through a Regimental Aid Post (RAP) and an Advanced Dressing Station (ADS). Casualties were picked up by helicopter and flown direct to hospital. Delays of 24 hours or more were frequent because of weather or darkness. The patrol orderly could carry only the bare minimum of equipment. The RMO was in touch with patrols by radio and sometimes he could go with the helicopter to collect the patient and accompany him back to hospital. This in general was the only opportunity for supportive treatment. He gave penicillin and streptomycin when indicated particularly to those with abdominal wounds. He could give dextran intravenously to a shocked patient, running in a pint quickly and. then maintaining the drip on the helicopter. He carried plaster slabs and a Thomas splint, although the standard Thomas splint was very bulky and cumbersome in this role particularly when the RMO had to be lowered by a rope into the jungle.

Based on the experience of Major Robert Scott, who drained a haemothorax in the

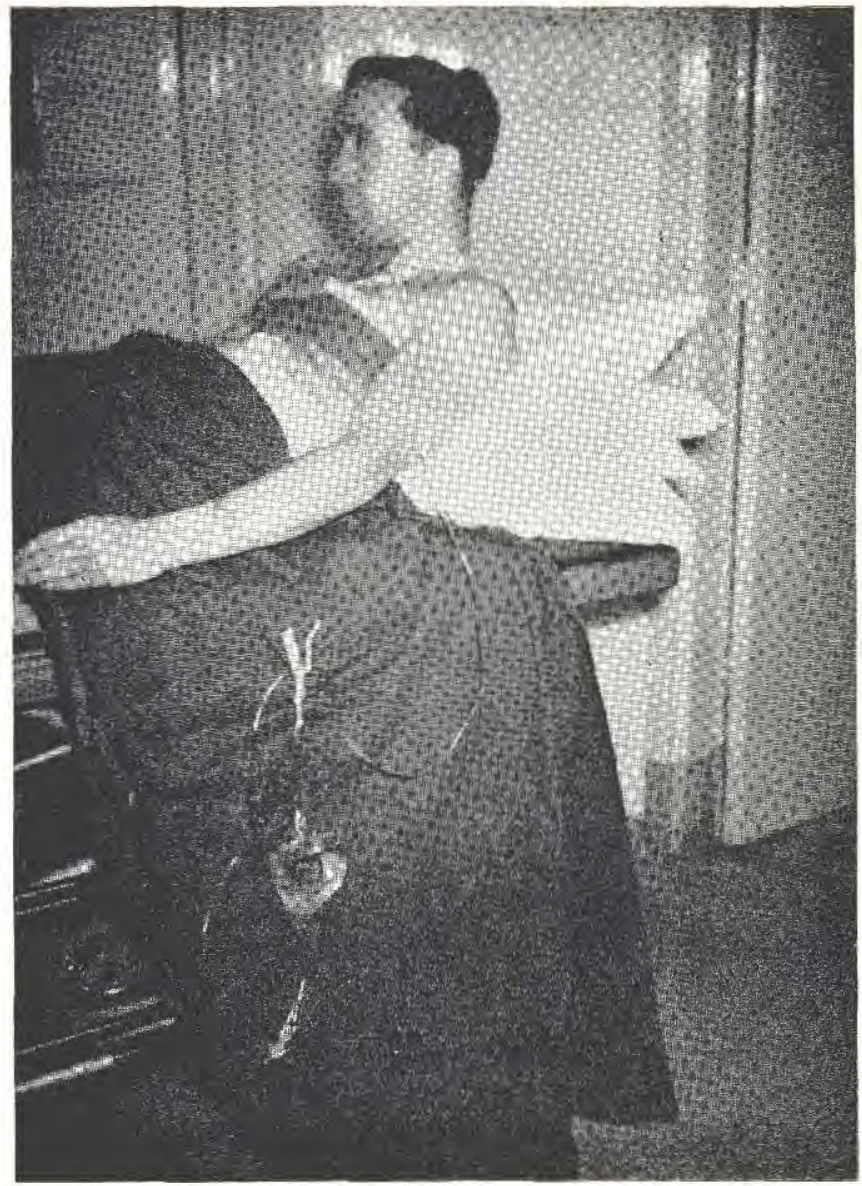

Fig. 2

'The "Steriflex" intravenous apparatus used for the relief of tension pneumothorax. 
FST at Kuching using the "Steriflex" intravenous saline apparatus as an underwater seal, RMOs were advised of this method to relieve respiratory distress due to tension pneumothorax or haemothorax. A nick was made in the "Steriflex" bag which was emptied of three quarters of its contents and suspended below the level of the patient. Figure 2 illustrates the relief of a tension pneumothorax with the needle in the second intercostal space.

\section{Analysis of Wounds}

There were 119 wounded over the two and a half years. These were graded into severe, moderate and trivial (Table 1.). Severe wounds were those involving the cranial; thoracic and abdominal cavities, those with major fractures or penetrating large joints, affecting major vessels or nerves and those with gross muscle damage. (Table 2-only

Table 1

Grading of Wounds January 1963 June 1965

$\begin{array}{llll}\text { SEVERE } & \cdots & & 51 \\ \text { MODERATE } & & \cdots & 53 \\ \text { TRIVIAL } & \cdots & \cdots & 15 \\ \text { TOTAL } & \ldots & \ldots & 119\end{array}$

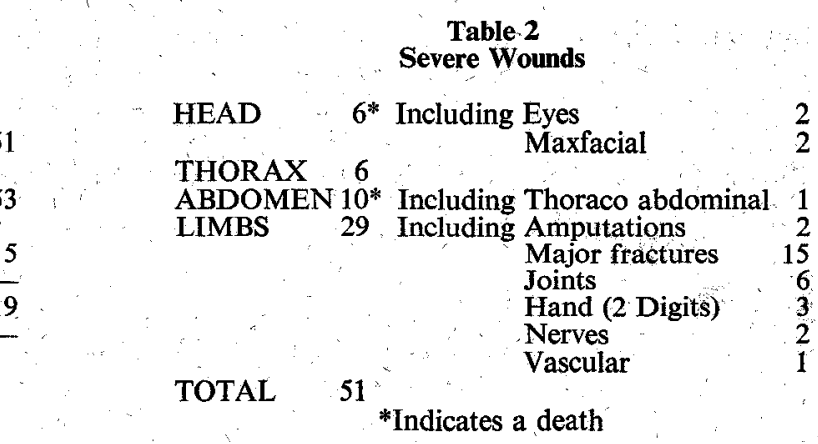

Table 2 2

..

.

.

2
5
6

.

.

the principal wound in each case has been enumerated). Moderate wounds were flesh wounds involving muscle with or without minimal bone damage.

\section{Mortality}

Mortality was low (Table 3) and reflected great credit on all concerned. Two casualties with brain injury and one with severe abdominal wounds perished.

Undoubtedly blood transfusion was a major factor promoting survival. At the end of World War II an average of 63 pints were given to one hundred patients (History of Second World War Surgery (1953)). In Korea the figure was 90 . In 71 patients passing through the FST in Borneo the amount of blood given was 99 pints (139 pints per 100 patients)*, but this series was too small on which to base an estimate for the future. It does indicate, however, that we must expect to use well over 100 pints per 100 casualties in any future war.

\section{Sepsis}

The incidence of sepsis was related to many factors particularly to the time interval between wounding and operation, the severity of the wound, the use of antibiotics, and to surgical skill and technique. Sepsis must be viewed in perspective for, although it may

\footnotetext{
* Since this paper was written, in a total of 148 wounded the average has risen to 150 pints per 100 casualties.
} 
be lethal and disabling, in many cases it causes only delay of a week or two in wound healing. In this series it caused little disability and then only in those cases which were graded as severe (Table 4). An analysis of the incidence of sepsis in relation to the time

Table 3

Mortality

3 Deaths in 119 Cases $=$ Brain damage $\div 2$

$$
=2.52 \%
$$

\section{Blood Used}

F.S.T. Kuching March 1964-June 1965

Wounded
Transfused
Blood used
Average transfusion $\quad \begin{aligned} & 71 \\ & -\quad 3.8 \text { Pints }\end{aligned}$

Average transfusion $\quad 3.8$ Pints
Table 4

Effects of Sepsis

Potential chronic osteomyelitis -4

Limb stiffness

Effects of empyema

$-6$

Delay in healingonly $\quad-30$

DEATHS - NIL

AMPUTATIONS - NIL

interval before operation (Table 5) suggests that in the moderate wounds 36 hours may

Table 5

THE RELATIONSHIP BETWEEN THE INCIOENCE OF SEPSIS

AND THE TIME INTERVAL BETWEEN WOUNOING AND OPERATION

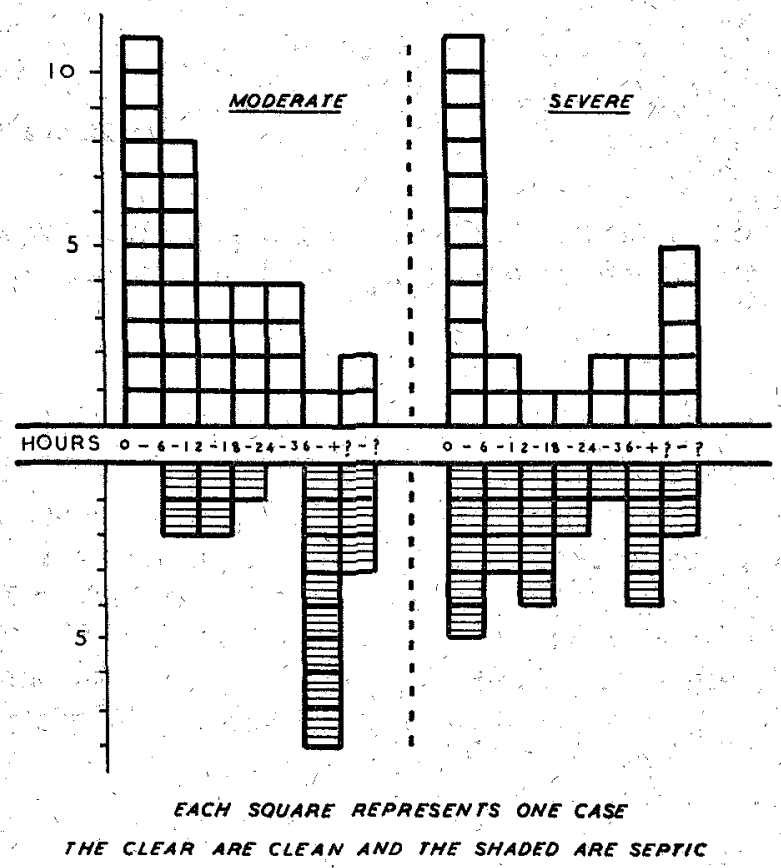

elapse with comparative safety under antibiotic cover, but the danger of gas gangrene arising from a small wound must never be forgotten. In the severe wounds which endanger life and limb the incidence of sepsis was higher. It is in these, particularly those involving bone, that sepsis may cause disability and the aim of operation within six hours of 
wounding must be maintained. These figures illustrate the importance of skilled triage at a busy forward surgical centre.

\section{The Initial Operation}

\section{Faults in Treatment}

However short the time interval and however much antibiotic is given sepsis will supervene if the surgical treatment is inadequate. In many of these cases the cause of sepsis could be traced to some fault in treatment, not so much to gross mismanagement, and to ignorance of the hard earned lessons of previous wars so well enumerated in the Field Surgery Pocket Book (1962), but to points of detail. In one case a golden rule was broken and a severely comminuted fracture of the femur was plated. This Gurkha soldier spent over a year in hospital and although the fracture united he had a chronic sinus. Fortunately in spite of his sinus and a sciatic nerve lesion he was retained in the service on base duties. A Gurkha soldier with abdominal wounds had large gut resected without colostomy and without retroperitoneal drainage in a small mission hospital. Blood transfusion, intravenous fluids and gastric suction, antibiotics, skilled surgical technique and devoted nursing saved him, but this must not be taken as a precedent.

Some superficial sepsis was due to a failure thoroughly to shave and cleanse the limb before operation. There was also superficial sepsis in thoracic and abdominal wounds. After closing the serous cavity the wound should be left open whenever possible to be closed later by delayed primary suture. The possible complication of empyema after the premature closure of the chest wall should be remembered.

After the complete debridement of a wound, including the opening up of the deep fascial compartments, nothing must be done to impede free drainage, and packing or partial suture should be avoided. In one case partial suture caused a constriction ring round a forearm allowing the pocketing of pus and bone necrosis. The application of "pHisoHex" cream into wounds was tried out but it did not seem to have any obyious advantage over a plain gauze dressing; in fact the use of this liquid probably encouraged the surgeon to plug the wound with a pack. Tulle gras tended to macerate the skin and because it might dam back secretions its use was not encouraged. The dressing must be adequate and completely cover the wound. The gauze should be covered by wool and then firmly fixed by strapping or bandage. If too small the dressing tends to slip and allow infection. Immobilization, even when there is no bony injury, is essential. Plasters should be as light as possible and of course split if they encircle the limb. The standard thoracobrachial plaster is adequate to splint an upper limb. Any attempt to abduct the arm in plaster is uncomfortable, does not immobilize it and encourages slipping of the dressings.

In hand wounds primary suture is permissible and every effort must be made to obtain closure but in two cases, operated on 18 and 24 hours after wounding, sepsis supervened after suture. At this stage the opportunity for safe closure had been lost. Because of the functional importance of the hand any wound involving more than two digits should be classed as severe and given a priority for treatment.

Maxillo-facial wounds have had to be undone at the base after suture and temporary fixation of the jaw in the forward area. These patients should be evacuated early to a maxillo-facial unit so that solid fixation and soft tissue repair can be performed in one stage. 


\section{Faults in Delayed Primary Suture}

Attention to detail is most important at this stage of treatment. Lack of it can undo the good work done by the forward surgeon. The overriding consideration in delayed primary suture (DPS) must be to avoid tension in the wound. The tissues are still oedematous four or five days after initial wound toilet and suture without tension may be impossible even when there has been no skin loss. In one case an artificial tension was created by injecting local anaesthetic and the wound broke down.

The most difficult wounds to close can be those of the forearm and of lower limb below the knee. In the latter the natural paucity of blood supply makes necrosis of skin and deep tissues a greater danger. Surgeon Lieutenant-Commander Hesketh, R.N., at the BMH Singapore, suggested leaving these wounds up to ten days to allow the oedema to settle before closure and practised this with success. When in doubt split skin grafts should be applied rather than closure by suture. Even when bone is exposed and the graft does not take over it little is lost. Bone does not die when it is exposed and covered. by a sterile dressing, but when its blood supply is cut off by tension within the wound, necrosis and spreading infection will follow. Tension is the one thing that must be avoided in all stages of wound healing.

Another fault noted at the stage of DPS concerned amputations. The forward surgeon should amputate at the lowest level of viable tissue and leave the stump wound open for DPS. The base surgeon must at the time of DPS consider the fitting of a prosthesis and reamputate at a higher level if necessary. The soldier will not be pleased if he must have a third operation before limb fitting.

The healing of wounds after DPS needs time and rest. The too early removal of sutures led to wound break down. This applied particularly to the mobile tissues around the shoulder and groin. Sutures should be left in for 14 days and the limb should be immobilised.

\section{Conclusions}

1. Every soldier must be trained in the fundamental principles of first aid.

2. Research is required to provide the isolated patrol with an effective antibiotic.

3. Moderate wounds in this theatre of war could be left under antibiotic cover for 36 hours before surgery. Severe wounds needed operation within six hours.

4. The requirement for blood in forward surgery is increasing. The provision of 100 pints per 100 casualties is an absolute minimum.

5. Skilled surgery, with attention to detail, in the forward area is fundamental for saving life and preventing sepsis.

6. "Delayed Primary Suture" is perhaps a misnomer. It" suggests a routine suture between the third and fifth days. To avoid tension developing at this stage each wound must be considered individually. "Delayed Closure" is perhaps a better term indicating skin cover by suture or skin graft without undue haste. 